\title{
"Teeth-anchorage': sleeping behavior of a Red Sea filefish on a branching coral
}
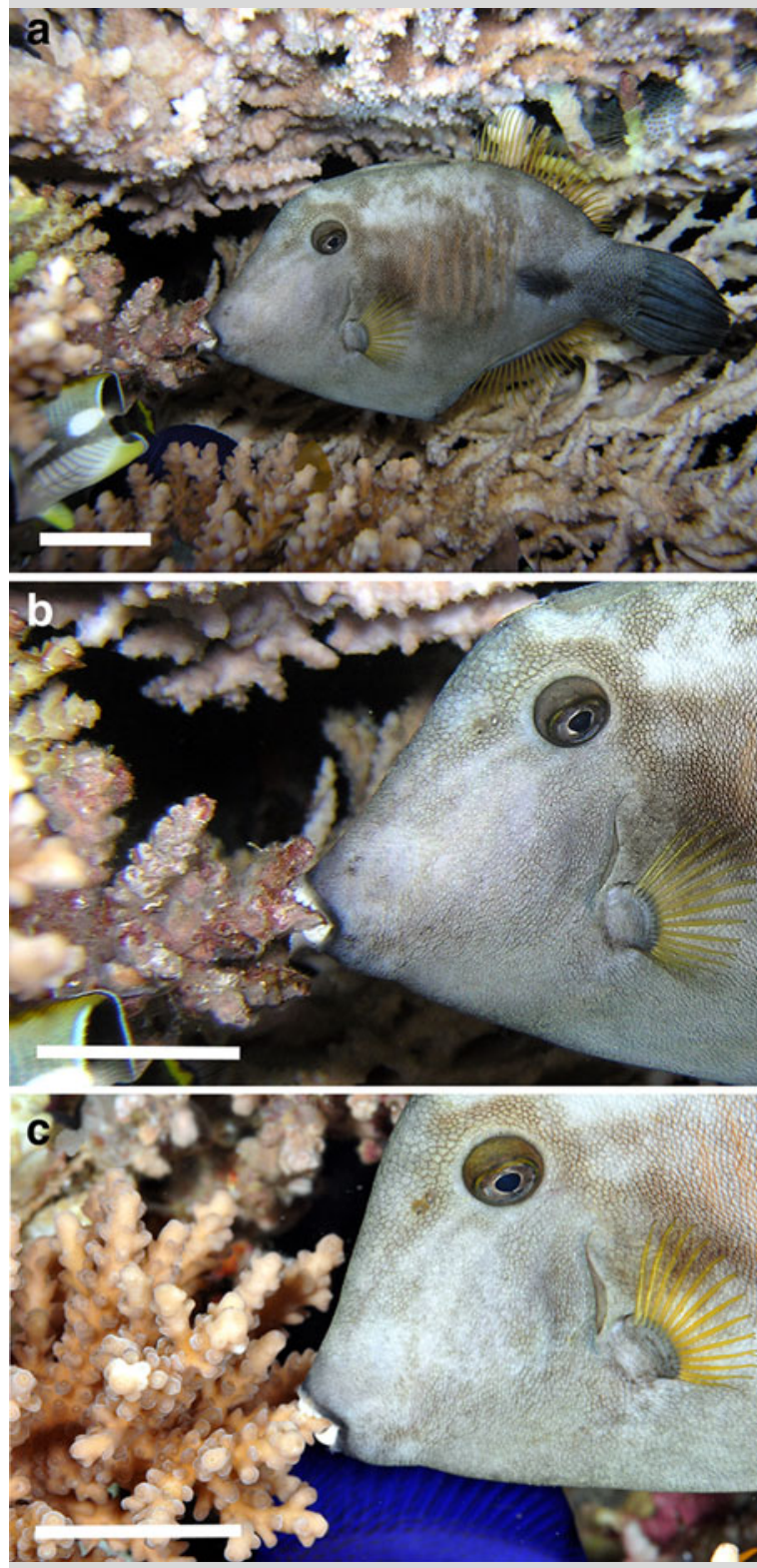

Fig. 1 The filefish Amanses scopas anchored on a tip of Acropora sp. colony (a) and (b). A few days after a severe southern storm the same individual changed its position and anchored on another nearby colony (c) scale: $5 \mathrm{~cm}$
During three weekly night dives (1 h each) in November 2010 on the coral reef of Eilat, Gulf of Aqaba (GOA), across from the Underwater Observatory, we observed a filefish Amanses scopes (Monacanthidae) (Cuvier, 1829), using its teeth to anchor itself onto a dead branch tip of a colony of the coral Acropora sp. (Fig. 1a, b). The filefish "parked" in a narrow space between the branches of the coral, undisturbed by the strong light emanating from our underwater torches and camera flash. The fish's eyes were motionless. Continued directed light, noise, and even gentle caressing did not cause the fish to escape, suggesting that it was sleeping. On December 11, 2010, an exceptionally severe southern storm took place in GOA that caused immense damage to the shallow water coral community, with hundreds of corals completely broken or damaged in our observation area. After the storm, during all our next seven weekly night dives (performed at different hours between 1900 and $0100 \mathrm{~h}$ ), we observed to our surprise the same fish anchoring on a different Acropora sp. colony, two meters away from the first colony, which had disappeared after the storm. Again, the filefish was using its teeth to hold onto the tip of a living branch (Fig. 1c).

Some members of the Monacanthidae are known to be territorial and have preferred sleeping spots (Wüest 1993). Here, however, we describe for the first time an "anchoring" sleeping behavior of Amanses scopes, unknown from other fishes. We believe that we observed the very same individual on all occasions, since this species is rare in the area (pers. obs.); in addition, we observed this fish six times during day time at the same site. Although it is known that filefish are corallivores (Randall 1964), we suggest that the negligible damage to the first coral, (visible in Fig. 1a, b), was not due to predation but rather to the night-after-night tooth-hold of the fish and concomitant branch-tip abrasion. We suggest that this sleeping behavior may prevent $A$. scopes from being swept away by strong currents, provide shelter from predators, keep the fish away from contact with the substratum (i.e., avoiding abrasion), and possibly prevent attack by ectoparasites (gnathiid isopods) known to attack fishes while sleeping on the substrate (Grutter et al. 2011).

\section{References}

Grutter AS, Crean AJ, Curtis LM, Kuris AM, Warner RR, McCormick MI (2011) Indirect effects of an ectoparasite reduce successful establishment of a damselfish at settlement. Funct Ecol 25:586-594

Randall JE (1964) A revision of the filefish genera Amanses and Cantherhines. Copeia 2:331-361

Wüest U (1993) Über des Schlafverhalten des Harlekin-Feilenfisches Oxymonacanthus halli. Natur und Museum 123(2):56-59

G. Eyal $(\bowtie)$ · L. Eyal-Shaham · Y. Loya: Department of Zoology, Tel-Aviv University, 69978 Tel-Aviv, Israel; e-mail: Galeyal@mail.tau.ac.il

G. Eyal · L. Eyal-Shaham: The Interuniversity Institute for Marine Sciences in Eilat, 88103 Eilat, Israel 